http://dx.doi.org/10.32929/2446-8355.2020v29n2p289-299

\title{
FERTILIZANTE DE LIBERAÇÃO CONTROLADA NO CRESCIMENTO INICIAL DA ORQUÍDEA Phalaenopsis sp.
}

Jean Carlo Baudraz de Paula ${ }^{1 *}$, Walter Aparecido Ribeiro Júnior ${ }^{1}$, Gabriel Danilo Shimizu ${ }^{1}$, Gabriel Barraca Men ${ }^{2}$, Ricardo Tadeu de Faria ${ }^{3}$

\footnotetext{
${ }^{1}$ Doutorando em Agronomia, Fitotecnia, Universidade Estadual de Londrina (UEL), Londrina, PR. *E-mail do autor correspondente: jc_baudraz@live.com

${ }^{2}$ Graduando do curso de Agronomia, Fitotecnia, Universidade Estadual de Londrina (UEL), Londrina, PR.

${ }^{3}$ Docente do curso de Agronomia, Fitotecnia, Universidade Estadual de Londrina (UEL), Londrina, PR.
}

Recebido: 27/03/2020; Aceito: 03/06/2020

RESUMO: A produção de orquídeas do gênero Phalaenopsis tem crescido nos últimos anos devido principalmente ao seu rápido crescimento e a produção de hastes florais com uma grande variedade de cores. Entre os fatores que afetam o crescimento e desenvolvimento destas plantas, a adequada nutrição é fundamental para obtenção de mudas de qualidade. $\mathrm{O}$ objetivo do trabalho foi avaliar o efeito de doses de osmocote ${ }^{\circledR}\left(15-09-12-\mathrm{N}_{-}-\mathrm{P}_{2} \mathrm{O}_{5}-\mathrm{K}_{2} \mathrm{O}\right.$, respectivamente) no desenvolvimento inicial da orquídea Phalaenopsis sp. O fertilizante osmocote $^{\circledR}$ foi adicionado nas seguintes doses: 0, 2, 4, 6, 8 e $10 \mathrm{~g} \mathrm{vaso}^{-1}$. Após doze meses foram avaliados: comprimento e largura média das folhas, área foliar total, massa seca da parte aérea e raiz e teores de clorofila $a, b$ e carotenoides. Dos substratos foram avaliados o $\mathrm{pH}$ e a condutividade elétrica. $\mathrm{O}$ comprimento e largura das folhas atingiram seu máximo nas doses de 4,7 e 5,0 g vaso ${ }^{-1}$, respectivamente. Para massa seca de folhas, raizes e área foliar total, as doses de máxima eficiência estimada foram 4,6, 3,5 e 4,5 $\mathrm{g}$ vaso $^{-1}$, respectivamente. O aumento nas doses de Osmocote ${ }^{\circledR}$ acarretou na morte das plantas na aplicação de $10 \mathrm{~g} \mathrm{vaso}^{-1}$. Doses estimadas entre 3,5 a $5,1 \mathrm{~g} \mathrm{vaso}^{-1}$ de Osmocote ${ }^{\circledR}$ (15-09-12) são recomendadas no desenvolvimento inicial da orquídea Phalaenopsis sp. por proporcionar incrementos na altura, largura, área foliar, massa seca da planta e nos pigmentos fotossintetizantes. Doses acima de $6 \mathrm{~g} \mathrm{vaso}^{-1}$ foram prejudiciais ao desenvolvimento devido ao aumento da condutividade elétrica e redução do $\mathrm{pH}$.

Palavras-chave: Adubação. Produção de mudas. Orchidaceae. Osmocote®.

\section{CONTROLLED RELEASE FERTILIZER IN INITIAL ORCHID GROWTH Phalaenopsis sp.}

\begin{abstract}
The production of orchids of the genus Phalaenopsis has grown in recent years mainly due to its rapid growth and the production of floral stems with a wide variety of colors. Among the factors that affect the growth and development of these plants, adequate nutrition is essential to obtain quality seedlings. The objective of the work was to evaluate the effect of doses of osmocote ${ }^{\circledR}\left(15-09-12-\mathrm{N}_{-} \mathrm{P}_{2} \mathrm{O}_{5}-\mathrm{K}_{2} \mathrm{O}\right.$, respectively) on the initial development of the orchid Phalaenopsis sp. The osmocote ${ }^{\circledR}$ fertilizer was added in the following doses: $0,2,4,6,8$ and $10 \mathrm{~g} \mathrm{vase}^{-1}$. After twelve months, average length and width
\end{abstract}


of the leaves, total leaf area, dry mass of the shoot system and root and levels of chlorophyll $a, b$ and carotenoids were evaluated. The substrates were evaluated for $\mathrm{pH}$ and electrical conductivity. The length and width of the leaves reached their maximum in the doses of 4.7 and $5.0 \mathrm{~g} \mathrm{vase}^{-1}$, respectively. For dry mass of leaves, roots and total leaf area, the doses of maximum estimated efficiency were 4.6, 3.5 and $4.5 \mathrm{~g} \mathrm{vase}^{-1}$, respectively. The increase in osmocote ${ }^{\circledR}$ doses resulted in the death of the plants in the application of $10 \mathrm{~g} \mathrm{vase}^{-1}$. Doses estimated between 3.5 to $5.1 \mathrm{~g} \mathrm{vase}^{-1}$ of Osmocote ${ }^{\circledR}(15-09-12)$ are recommended in the initial development of the orchid Phalaenopsis sp. for providing increases in height, width, leaf area, dry mass of the plant and in photosynthetic pigments. Doses above $6 \mathrm{~g} \mathrm{vaso}^{-1}$ started to be detrimental to development due to the increase in electrical conductivity and reduced $\mathrm{pH}$.

Key words: Fertilization. Seedling production. Orchidaceae. Osmocote®.

\section{INTRODUÇÃO}

A floricultura constitui-se de um dos segmentos mais dinâmicos do agronegócio brasileiro, tornando-se uma atividade atrativa aos produtores, e seu cultivo tem crescido consideravelmente no Brasil (JUNQUEIRA; PEETZ, 2008). Dentre os destaques na comercialização de flores estão as rosas, crisântemos, lírios, gérberas, azaleias e orquídeas (JUNQUEIRA; PEETZ, 2008).

A família Orchidaceae é uma das maiores em números de espécies entre as angiospermas, com 27.081 representantes distribuídas em 899 gêneros (THE PLANT LIST, 2020). São plantas de habitat terrestre, rupestre, aquático, e pode ser saprófitas ou epífitas (REFLORA, 2020). No Brasil, são citadas 2.420 espécies distribuídas em 207 gêneros (REFLORA, 2020). Destacam-se as plantas do gênero Phalaenopsis, nativas do Norte da Austrália e de alguns países da Ásia como Índia e Filipinas. As plantas Phalaenopsis são popularmente conhecidas como "orquídea borboleta", pois a forma de sua flor lembra uma mariposa de asas abertas (TUSKES; TUSKES, 2002).

A produção de orquídeas Phalaenopsis apresentou crescimento extraordinário nos últimos anos. A potencialidade do mercado brasileiro pode ser comprovada por dados fornecidos pelo Instituto Brasileiro de Floricultura - IBRAFLOR. A análise do número de produtores e atacadistas de Phalaenopsis no Brasil demonstra aumento nos últimos cinco anos. No mês de outubro de 2011 a empresa Veiling de Holambra-SP produziu 302 mil vasos de Phalaenopsis, um aumento de $40 \%$ em relação ao mesmo período do ano de 2010. Outro destaque foi o aumento de quase $42 \%$ na produção em novembro de 2012 quando comparado ao mesmo período em 2011. Isso mostra o quanto estas orquídeas são consumidas e as fazem ficar em destaque no comércio de plantas em vaso (IBRAFLOR, 2013).

Em cultivos comerciais, geralmente faz-se uso de ambiente controlado com alta densidade de plantas, dessa forma, a fertilização torna-se indispensável para o bom crescimento e desenvolvimento das orquídeas. A produção comercial de plantas ornamentais é extremamente dependente de qualidade e padronização, aspectos estes que podem ser garantidos por uma boa nutrição de plantas (NETO; BOLDRIN; MATSSON, 2015). 
Todavia, as recomendações de adubação para orquídeas, se fundamentam, principalmente, na experiência de produtores, além do que, os fertilizantes disponíveis não foram desenvolvidos considerando as especificidades de cada espécie e seus estádios de desenvolvimento, podendo acarretar em redução na qualidade final e aumento dos custos de produção (NETO; BOLDRIN; MATSSON, 2015).

A falta de pesquisas relacionadas às demandas nutricionais das orquídeas além da não existência de uma recomendação genérica de fertilização para orquídeas acaba que nem sempre atendem as exigências nutricionais das diferentes espécies. As orquídeas de modo geral possuem um crescimento lento que associada a limitação nutricional pode prolongar ainda mais seu tempo de cultivo (ALVES et al., 2017).

Uma alternativa para a produção de plantas é o uso de fertilizantes de liberação lenta ou controlada, os quais são solúveis e agrupados em grânulos recobertos por resina orgânica ou elástica. A liberação lenta é fundamental para que se minimizem os problemas como a queima das raízes por excesso de adubação, a salinidade do substrato, reduzindo também perdas dos nutrientes por lixiviação, diminuindo a mão-de-obra para adubações posteriores, e como vantagem mantem as plantas nutridas constantemente durante todo período de desenvolvimento (DINALLI et al., 2012).

O osmocote ${ }^{\circledR}$ é um adubo composto principalmente por NPK, e em menores quantidades são encontrados $\mathrm{S}, \mathrm{Mg}, \mathrm{Fe}, \mathrm{Mn}, \mathrm{Cu}, \mathrm{Zn}, \mathrm{B}$ e $\mathrm{Mo}$, fabricado em diferentes formulações, proporcionando a liberação lenta dos nutrientes, de 3 a 18 meses, dependendo do revestimento. Pelo fato do osmocote ${ }^{\circledR}$ permitir a disponibilidade contínua de nutrientes para as mudas, durante um maior tempo, existe menor possibilidade de ocorrer deficiência de nutrientes, reduzindo assim os custos operacionais na formação da muda. Trata-se de um fertilizante indicado tanto para produção de mudas de algumas frutíferas como ornamentais e oleráceas (DINALLI et al., 2012).

Apesar de produtos como o osmocote ${ }^{\circledR}$ serem recomendados como fertilizante para orquídeas, estudos relacionando doses adequadas no crescimento de Phalaenopsis sp. são escassos. Desta forma, o objetivou-se avaliar o efeito de doses de osmocote ${ }^{\circledR}$ no desenvolvimento inicial da orquídea Phalaenopsis sp.

\section{MATERIAL E MÉTODOS}

O experimento foi conduzido de janeiro de 2018 a janeiro de 2019 na Universidade Estadual de Londrina - UEL (23⒉ $3^{\prime} \mathrm{S} ; 51^{\circ} 11^{\prime} \mathrm{W} ; 566 \mathrm{~m}$ de altitude), em casa de vegetação climatizada modelo Van der Hoeven ${ }^{\circledR}$, coberta com placas de policarbonato transparente e difusor, com retenção luminosa de $50 \%$, através de tela de sombreamento Aluminet ${ }^{\circledR}$ e temperatura controlada de $28^{\circ} \mathrm{C} \pm 3^{\circ} \mathrm{C}$ pelo sistema humid cold. A irrigação foi manual, adicionando uma lâmina de água de $6 \mathrm{~mm}$, diariamente, no período da manhã, para todos os tratamentos.

Plantas clonadas de Phalaenopsis sp. foram obtidas por propagação in vitro, aclimatizadas em bandejas de isopor e, após seis meses ex vitro, transplantadas para vasos plásticos. Para fins de padronização o comprimento médio das folhas utilizadas no 
experimento foi de $5 \pm 1,0 \mathrm{~cm}$. Foram utilizados vasos plásticos, com 9,8 cm, 13,0 cm e 10,0 $\mathrm{cm}$ de altura, diâmetro superior e inferior respectivamente, e volume de 1L. Estes foram preenchidos com substrato, sendo este composto de uma mistura de casca de pinus e carvão vegetal, peneirado entre as peneiras de malha 1,5 e $0,5 \mathrm{~cm}$, e misturados em proporções iguais (1v: 1v). No fundo de cada vaso foi adicionada uma camada de fragmentos cerâmicos para facilitar a drenagem.

O fertilizante comercial utilizado no experimento foi o osmocote ${ }^{\circledR}(15-09-12$, N-P2O5$\mathrm{K} 2 \mathrm{O}$, respectivamente) além da presença de $\mathrm{S}(6 \%), \mathrm{Mg}(1,3 \%), \mathrm{Fe}(0,46 \%), \mathrm{Mn}(0,06 \%), \mathrm{Cu}$ $(0,05 \%)$ e Mo $(0,02 \%)$ (Forth Cote $®)$, sendo adicionado nas seguintes doses: 0, 2, 4, 6, 8 e 10 g vaso-10 fertilizante foi aplicado nas concentrações de cada tratamento sobre o substrato de forma homogênea a cada intervalo de 90 dias, na quantidade descrita para cada tratamento, sendo realizado ao todo quatro aplicações durante o experimento.

Após doze meses as plantas foram removidas do substrato e lavadas em água corrente para as avaliações das seguintes variáveis: comprimento e largura média das folhas, área foliar total, massa seca da parte aérea e raiz, além dos teores de clorofila $a, b$ e carotenoides. Dos substratos foram avaliados o $\mathrm{pH}$ e a condutividade elétrica (CE).

O comprimento e a largura foram mensurados a partir da maior folha com o auxílio de uma régua graduada em centímetros. A área foliar (AF) foi mensurada por análise de imagem. A determinação da área foliar foi realizada pelo processamento destas no programa SisCob. As folhas foram destacadas e dispostas sobre uma superfície lisa com coloração homogênea e posteriormente fotografadas junto a uma referência de área conhecida com coloração contrastante.

A massa seca foi determinada pela secagem dos tecidos em estufa, com ventilação forçada de ar à temperatura de $65{ }^{\circ} \mathrm{C}$, até obtenção de massa constante (período de uma semana). Após a secagem os tecidos foram pesados em balança semianalítica com precisão de $0,001 \mathrm{~g}$.

Para a determinação dos teores de clorofila $(a$ e $b$ ) e carotenoides seguiu a metodologia descrita por Whitham, Blaydes e Devlin (1971). Os tecidos frescos de folhas foram pesados $(0,2 \mathrm{~g})$, macerados em nitrogênio líquido, e posteriormente transferidos para um tubo contendo acetona (100\%). Estes tubos foram envoltos por papel alumínio e armazenados em refrigeração $\left(10 \pm 2{ }^{\circ} \mathrm{C}\right)$ durante uma semana. Na sequência, os extratos foram centrifugados, e dos sobrenadantes foram realizadas leituras da absorbância (A) em espectrofotômetro nos comprimentos de 663, 645 e $434 \mathrm{~nm}$ para os teores de clorofila $a, b$ e carotenoides respectivamente. Os teores foram calculados através das seguintes equações (1), (2) e (3):

clorofila $a=(11,24 \times$ A663 - 2,04 x A645)

clorofila $b=(20,13 \times$ A645 - 4,19 x A663)

carotenoides $=(1000 \times$ A434 $-1,90$ clorofila $a-63,14$ clorofila $b) / 214$

Sendo:

A - absorbância;

$\mathrm{O} \mathrm{pH}$ e a condutividade elétrica dos substratos foram determinados seguindo metodologia descrita por (ABREU et al., 2007), pelo método de extração (1v: 5v) de 
substrato e água deionizada, e a leitura realizada com o auxílio de um pHmetro e condutivímetro portátil.

O delineamento experimental utilizado foi inteiramente casualizado com sete repetições. Os dados foram submetidos à análise de normalidade e homogeneidade de variância através dos testes de Shapiro Wilk e Hartley respectivamente, e posteriormente submetidos à análise de variância. As variáveis que apresentaram diferenças significativas foram submetidas à análise de regressão. Os dados foram processados utilizando o software R através do pacote stats (R CORE TEAM, 2019), considerando um nível de significância de $5 \%$ de probabilidade de erro.

\section{RESULTADOS E DISCUSSÃO}

O aumento das doses de osmocote ${ }^{\circledR}$ promoveu efeito positivo no comprimento, largura e área foliar de Phalaenopsis sp. (Figura 1), entretanto, a aplicação de $10 \mathrm{~g} \mathrm{vaso}^{-1}$ resultou na morte das plantas. Para o comprimento médio das folhas, foi possível estimar uma dose de máxima eficiência em $4,7 \mathrm{~g}$ vaso ${ }^{-1}$, atingindo $17,0 \mathrm{~cm}$ nesta dose. A variável largura média das folhas teve sua dose máxima estimada em $5,0 \mathrm{~g} \mathrm{vaso}^{-1}$, obtendo $8,7 \mathrm{~cm}$ médio das folhas. Para área foliar total o máximo obtido foi de $426,2 \mathrm{~cm}^{2}$ na dose máxima estimada de $4,5 \mathrm{~g}$ vaso ${ }^{-1}$.
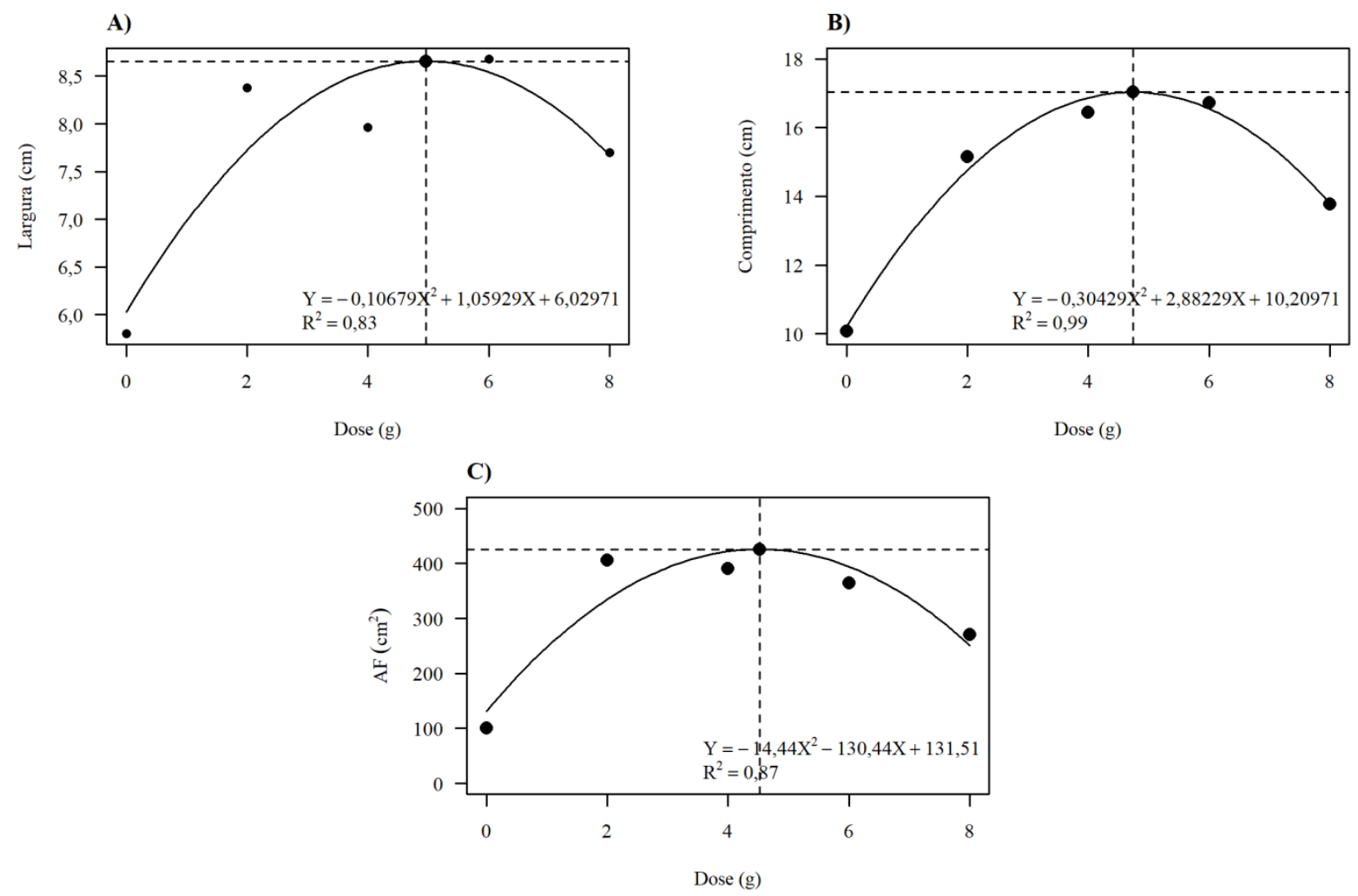

Figura 1. Ajustes de regressão quadrática para as variáveis: A) Largura e B) comprimento médio das folhas e C) área foliar total (AF) em função de doses de osmocote® após 12 meses de cultivo de Phalaenopsis sp. Londrina-PR, 2018. Quadratic regression adjustments for the variables: A) Width and B) Average leaf length and C) Total leaf area (AF) as a function of osmocote ${ }^{\circledR}$ doses after 12 months of cultivation of Phalaenopsis sp. Londrina-PR, 2018.

Fonte: Autoria própria. Own authorship. 
Este comportamento das curvas para as variáveis avaliadas segue a lei dos incrementos decrescentes, na qual os incrementos em produção são cada vez menores. Deste modo, a curva de crescimento é caracterizada por três fases: aumento, estabilização e redução do crescimento, que correspondem a um fornecimento baixo, suficiente e excessivo de nutrientes (MALAVOLTA, VITTI; OLIVEIRA, 1997).

O mesmo padrão de ajuste quadrático foi verificado para massa seca da raiz e parte aérea (Figura 2). A massa seca obteve doses máximas estimadas em 4,6 e 3,5 g vaso-1 ${ }^{-1}$ nestas doses os valores atingiram 5,70 e 12,73 g para os tecidos de parte aérea e raiz, respectivamente. Foi possível observar ponto de máxima eficiência para todas variáveis fitométricas, indicando um comportamento quadrático para doses.
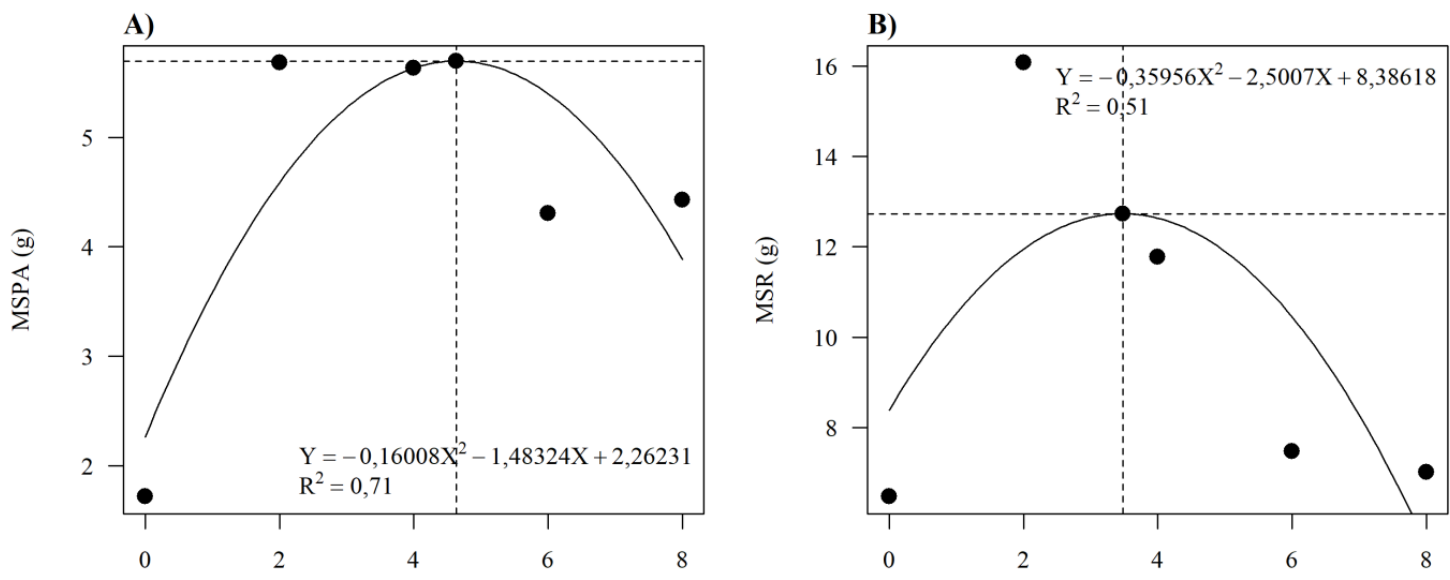

Figura 2. Ajustes de regressão quadrática para as variáveis: A) Massa seca da parte aérea (MSPA) e B) raiz (MSR) em função de doses de osmocote® após 12 meses de cultivo de Phalaenopsis sp. Londrina-PR, 2018. Quadratic regression adjustments for the variables: A)

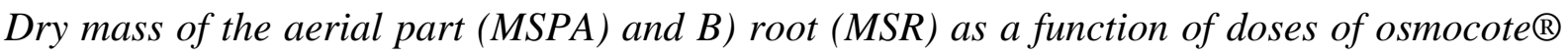
after 12 months of cultivation of Phalaenopsis sp. Londrina-PR, 2018.

Fonte: Autoria própria. Own authorship.

Esse resultado foi semelhante ao obtido por Campos et al. (2009) em que o uso de osmocote ${ }^{\circledR}$ promoveu maior desenvolvimento das mudas micropropagadas de Anthurium maricense Nadruz \& Mayo na fase de aclimatização, com redução das variáveis avaliadas com o aumento da dose.

A redução dos valores fitométricos, verificado nas maiores doses de osmocote ${ }^{\circledR}$, pode estar relacionado a salinidade provocado pelo excesso de nutrientes no substrato. Um dos efeitos comuns da salinidade nas plantas é a diminuição no crescimento, visto que o aumento da concentração de sais no substrato reduz o potencial hídrico, diminuindo a disponibilidade de água pelas raízes e comprometendo a absorção de nutrientes, com isso afetando todas variáveis fitométricas analisadas (CONCEIÇÃO, 2015).

Para os pigmentos os ajustes também seguiram a tendência quadrática, com tendência de aumento até certa dose e posterior redução (Figura 3). Todos os pigmentos responderam ao aumento da dose de osmocote ${ }^{\circledR}$, provavelmente em decorrência do aumento de nutrientes. Para clorofila $a$ e $b$, o máximo de teor destes foram obtidos nas doses estimadas de $5,1 \mathrm{~g}$, com teores de 6,49 e $2,77 \mathrm{mg} \mathrm{g}^{-1}$, respectivamente. Para os carotenoides, a dose de máxima 
eficiência também foi verificada com $5,1 \mathrm{~g}$ de osmocote ${ }^{\circledR}$, resultando em $6,31 \mathrm{mg} \mathrm{g}^{-1}$ deste pigmento.
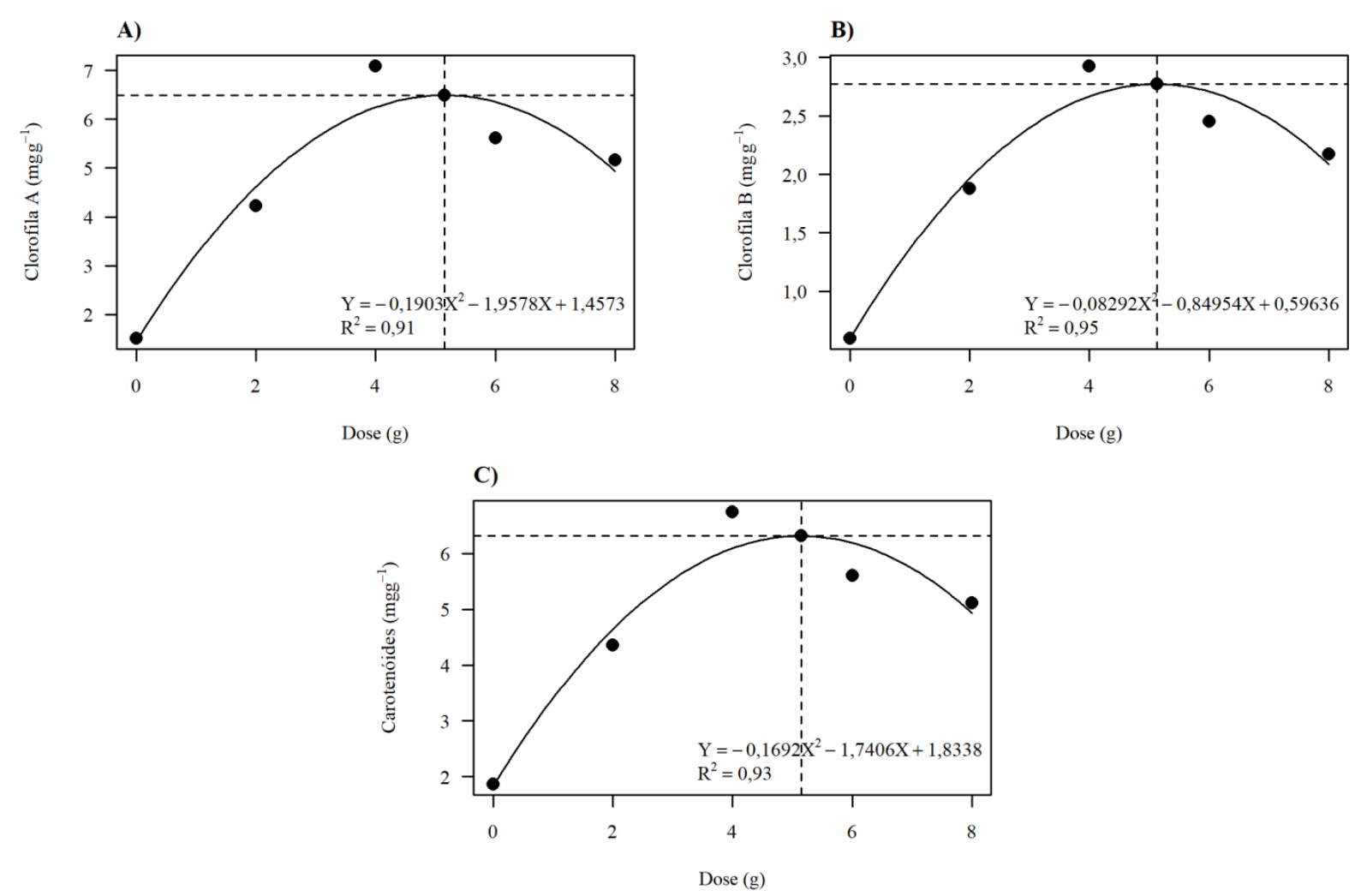

Figura 3. Ajustes de regressão linear para as variáveis: A) teor de clorofila $a$, B) clorofila $b$ e de C) carotenoides nas folhas, em função de doses de osmocote ${ }^{\circledR}$ após 12 meses de cultivo de Phalaenopsis sp. Londrina-PR, 2018. Linear regression adjustments for the variables: A) chlorophyll $a, B$ ) chlorophyll $b$ and $C$ ) carotenoid content in the leaves, as a function of doses of osmocote ${ }^{\circledR}$ after 12 months of cultivation of Phalaenopsis sp. Londrina-PR, 2018.

Fonte: Autoria própria. Own authorship.

Este aumento nos teores de clorofila com aumento de dose do adubo de liberação lenta (osmocote $®$ ) era esperado, visto que estes valores refletem de forma indireta nas concentrações de $\mathrm{N}$ e $\mathrm{Mg}$ nas folhas, uma vez que estes nutrientes fazem parte da estrutura das clorofilas. Assim, existe uma correlação entre as concentrações de clorofila e o estado nutricional da planta (TAIZ et al., 2016).

A resposta quadrática observada para os pigmentos também foi verificado por Pias et al. (2013), estudando doses de osmocote ${ }^{\circledR}$ na produção de mudas de Grápia (Apuleia leiocarpa (Vogel) J.F.Macbr.), em que as doses influenciaram as concentrações de clorofila até um ponto de máximo, com posterior declínio.

A queda dos teores de clorofila e carotenoides em doses maiores pode ter ocorrido pelo fato das plantas não suportarem a maior dose recomendada pelo fabricante, devido ao excesso de nutrientes disponibilizados serem maior do que o necessário para seu crescimento inicial, o que acabou prejudicando as concentrações dos pigmentos. Para Munns e Tester (2008), o excesso de nutrientes pode estimular a atividade enzimática da clorofilase que degrada as 
moléculas dos pigmentos fotossintetizantes e induz a destruição estrutural dos cloroplastos, provocando também o desbalanceamento e perda de atividade das proteínas de pigmentação.

Para as características químicas do substrato, observou-se incremento para a condutividade elétrica e redução do pH em função do aumento das doses do adubo (Figura 4). Houve um efeito inverso para estas variáveis com o aumento da dose, onde o pH teve redução de 6,2 no tratamento controle para 3,9 na maior dose. Enquanto, a condutividade elétrica aumentou de $100 \mu \mathrm{S} \mathrm{cm}^{-1}$ para mais de $1700 \mu \mathrm{S} \mathrm{cm}^{-1}$.
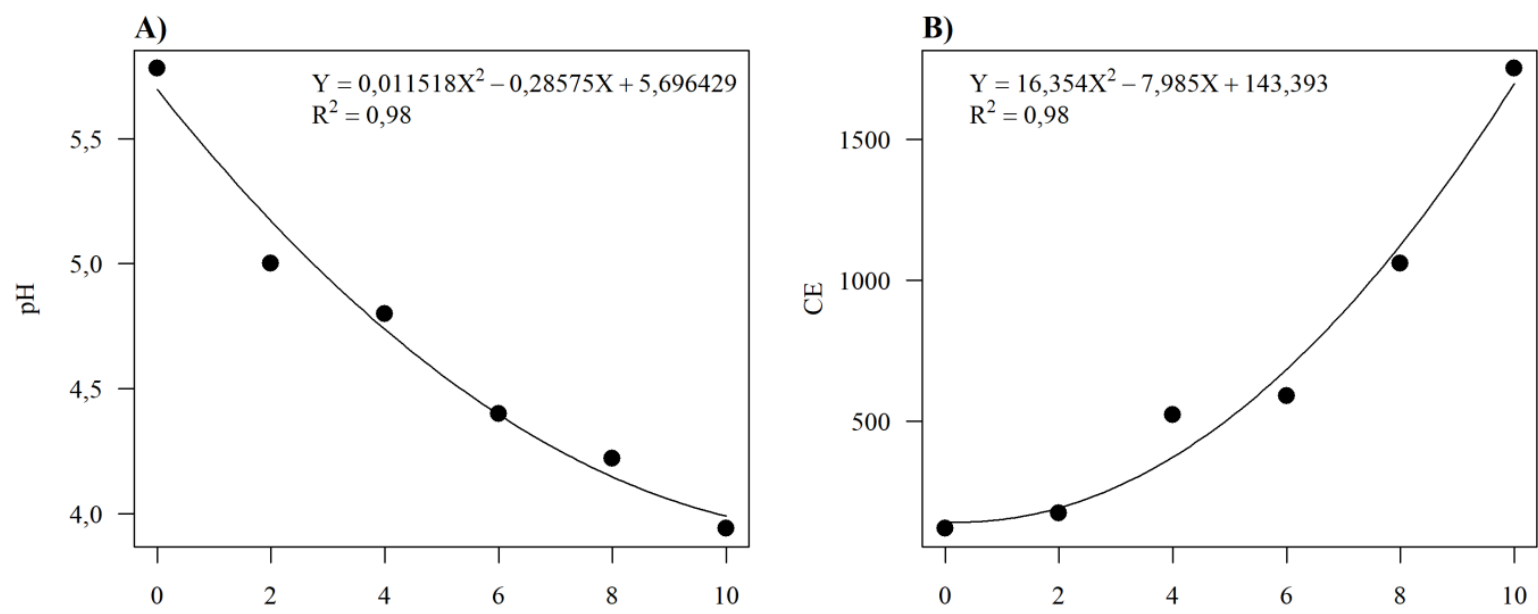

Figura 4. Ajustes de regressão para as variáveis: A) pH e B) condutividade elétrica em função de doses de osmocote ${ }^{\circledR}$ após 12 meses de cultivo de Phalaenopsis sp. Londrina-PR, 2018. Regression adjustments for the variables: A) $p H$ and B) electrical conductivity as a function of doses of osmocote ${ }^{\circledR}$ after 12 months of cultivation of Phalaenopsis sp. LondrinaPR, 2018.

Fonte: Autoria própria. Own authorship.

Para Takane, Yanagisawa e Góis (2013), condutividades elétricas entre 360 a $650 \mu \mathrm{S} \mathrm{cm}^{-1}$ são normais para o crescimento das plantas ornamentais, sendo que valores acima de $660 \mu \mathrm{S} \mathrm{cm}^{-1}$ podem reduzir o vigor e o crescimento. Deste modo, considerando que a condutividade na dose $6 \mathrm{~g} \mathrm{vaso}^{-1}$ de osmocote ${ }^{\circledR}$ apresentou valores próximos ao limite superior, pode-se inferir que a redução no crescimento observado neste tratamento esteve relacionado ao estresse salino, sendo inadequada para o crescimento de Phalaenopsis sp.

$\mathrm{O}$ estresse salino causado pelo aumento da condutividade elétrica reduz o crescimento das plantas, pois diminui o potencial de água, e consequentemente a absorção de água e nutrientes, causando a diminuição das taxas de elongamento e divisão celular (MUNNS; TESTER, 2008). Em Phalaenopsis sp. o aumento da salinidade resultou na morte de raizes as quais se tornam ocas (WANG, 1998). O mesmo ocorreu nas plantas adubadas com $10 \mathrm{~g}$ vaso $^{-1}$, onde a condutividade atingiu $1751 \mu \mathrm{S} \mathrm{cm}^{-1}$, valor bem acima do recomendado e ocasionando a morte destas plantas.

A redução do $\mathrm{pH}$, ou seja, a acidificação do substrato ocorre devido ao crescimento das raízes e consequentemente das plantas, que é dependente da absorção de nutrientes. Durante o processo de absorção as raízes geram potencial eletroquímico através da protrusão transmembranar de $\mathrm{H}^{+}$, mediado por bombas e gasto de ATP (TAIZ et al., 2016). 
Apesar das variações existentes no $\mathrm{pH}$, os valores observados nos substratos de ambos os fertilizantes, incluindo o mineral, ficaram dentro do intervalo considerado adequado para o crescimento das orquídeas, que deve ser ácido, entre 4,8 a 6,2 (TAKANE; YANAGISAWA; PIVETTA, 2010). Porém, em doses acima de $6 \mathrm{~g} \mathrm{vaso}^{-1} \mathrm{o} \mathrm{pH}$ foi muito baixo, reduzindo o desenvolvimento das plantas e ocasionando até a morte das mesmas na dose de $10 \mathrm{~g}$ vaso $^{-1}$, em que o pH chegou a 3,9. A utilização do fertilizante de liberação lenta (osmocote®) promoveu incrementos ao crescimento de Phalaenopsis sp. (Figura 5).

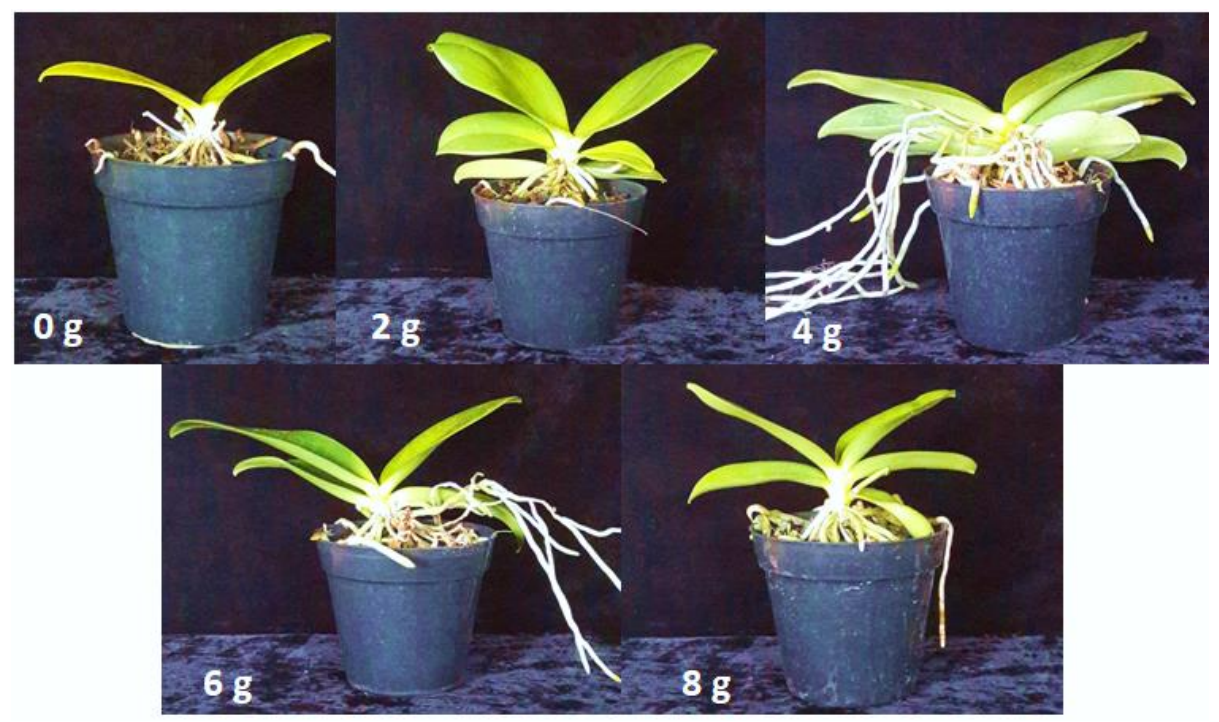

Figura 5. Plantas de Phalaenopsis sp. fertilizadas com doses crescentes de osmocote ${ }^{\circledR}$ após 12 meses de cultivo em casa de vegetação. Londrina-PR, 2018. Plants of Phalaenopsis sp. fertilized with increasing doses of osmocote ${ }^{\circledR}$ after 12 months of cultivation in a greenhouse. Londrina-PR, 2018.

Fonte: Autoria própria. Own authorship.

\section{CONCLUSÃO}

Doses estimadas entre 3,5 a $5,1 \mathrm{~g} \mathrm{vaso}^{-1}$ de Osmocote ${ }^{\circledR}$ (15-09-12) são recomendadas no desenvolvimento inicial da orquídea Phalaenopsis sp. por proporcionar incrementos na altura, largura, área foliar, massa seca da planta e nos pigmentos fotossintetizantes. Entretanto, doses acima de $6 \mathrm{~g} \mathrm{vaso}^{-1}$, são prejudiciais ao desenvolvimento devido ao aumento da condutividade elétrica e redução do $\mathrm{pH}$ no substrato.

\section{AGRADECIMENTOS}

A Coordenação de Aperfeiçoamento de Pessoal de Nível Superior (CAPES) e ao Conselho Nacional de Desenvolvimento Científico e Tecnológico (CNPq) pelo apoio financeiro e a Universidade Estadual de Londrina (UEL).

\section{REFERÊNCIAS BIBLIOGRÁFICAS}

ABREU, M. F.; ABREU, C. A.; SARZI, I.; JUNIOR, A. L. P. Extratores aquosos para a caracterização química de substratos para plantas. Horticultura Brasileira, Brasília, v. 25, n. 
2, p.184-187, 2007. Disponível em: http://dx.doi.org/10.1590/S0102-05362007000200011. Acesso em: dia mês ano. Acesso em: 27 out. 2019.

ALVES, G. A. C.; HOSHINO, R. T.; BERTONCELLI, D. J.; FREIRIA, G. H.; FURLAN, F. F.; OMURA, M. S.; STEGANI, V.; FARIA, R. T. Adubação mineral e orgânica no crescimento da orquídea brasileira Oncidium baueri Lindl. Journal of Agronomic Sciences, Madison, v. 6, n. 1, p.163-172, 2017.

CAMPOS, A. S.; BOMFIM, G. V.; CARVAlHO, A. C. P.; AZEVEDO, B. M.; TANIGUCHI, C. A. K. Doses de Osmocote® na aclimatização de mudas micropropagadas de Anthurium maricense. Revista Agro@mbiente On-line, Boa Vista, v. 13, p.14-23, 2019. Disponível em: http://doi.org/10.18227/1982-8470ragro.v13i0.5348. Acesso em: 20 out. 2019.

CONCEIÇÃO, S. S. Aclimatação de plantas de girassol à salinidade induzida por silício. 2015. 83 f. Dissertação (Mestrado em Agronomia) - Universidade Federal do Ceará, Fortaleza, 2015.

DINALLI, R. P.; CASTILHO, R. M. M.; GAZOLA, R. N. Utilização de adubos de liberação lenta na produção de mudas de Vigna radiata L. Revista Científica Eletrônica de Agronomia, Rio de Janeiro, v. 2, n. 1, p.10-15, 2012.

NETO, A.C.; BOLDRIN, K. V. F.; MATSSON, N. S. Nutrition and Quality in Ornamental Plants. Horticultura Brasileira, Brasília, v. 21, n. 2, p.139-150, 2015. Disponível em: https://doi.org/10.14295/aohl.v21i2.809. Acesso em: dia mês ano. Acesso em: 12 out. 2019.

INSTITUTO BRASILEIRO DE FLORICULTURA - IBRAFLOR. Números do Setor. Disponível em: http://www.ibraflor.com/publicacoes/vw.php?cod=189. Acesso em: 15 ago. 2019.

JUNQUEIRA, A. H.; PEETZ, M. S. Mercado interno para os produtos da floricultura brasileira: características, tendências e importância socioeconômica recente. Revista Brasileira de Horticultura Ornamental, Campinas, v. 14, n. 1, p.37-52, 2008.

MALAVOltA, E.; VITTI, G. C.; OLIVEIRA, S. A. Avaliação do estado nutricional das plantas: princípios e aplicações. Piracicaba: Potafos. 1997. 319 p.

MUNNS, R.; TESTER, M. Mechanisms of salinity tolerance. Annual Review of Plant Biology, Palo Alto, v. 59, n. 1, p.651-681, 2008. Disponível em: https://doi.org/10.1146/annurev.arplant.59.032607.092911. Acesso em: 13 out. 2019.

PIAS, O.; CANTARELlI, E. B.; BERGHETTI, J.; LESCHEWITZ, R.; KLUGE, E. R.; SOMAVILLA, L. Doses de fertilizante de liberação controlada no índice de clorofila e na produção de mudas de grápia. Pesquisa Florestal Brasileira, Colombo, v. 33, n. 73, p.19-25, 2013. Disponível em: http://dx.doi.org/10.4336/2013.pfb.33.73.419. Acesso em: 18 out. 2019.

R DEVELOPMENT CORE TEAM. R: A language and environment for statistical computing. R Foundation for Statistical Computing, Vienna, Áustria. Disponível em http://www.r-project.org. Acesso em 04 ago. 2019. 
REFLORA. Orchidaceae in Flora do Brasil 2020 em construção. Jardim Botânico do Rio de Janeiro. Disponível em: http://reflora.jbrj.gov.br/reflora/floradobrasil/FB179. Acesso em 14 jan. 2010.

TAIZ, L.; ZEIGER, E.; MOLLER, I. M.; MURPHY, A. Fisiologia e Desenvolvimento Vegetal. 6. ed. Porto Alegre: ArtMed. 2016. 888 p.

TAKANE, R. J.; YANAGISAWA, S. S.; GÓIS, E. A. Técnicas em substratos para a floricultura. Fortaleza: Expressão gráfica e Editora, 2013. 148 p.

TAKANE, R. J.; YANAGISAWA, S. S.; PIVETTA, K. F. L. Cultivo moderno de orquídeas: Cattleya e seus híbridos. Fortaleza: UFC, 2010. 179 p.

THE PLANT LIST. A working list of all plant species. Disponível em: http://www.theplantlist.org/. Acesso em: 23 jan. 2020.

TUSKES, P.; TUSKES, A. Culture of Phalaenopsis species. Orchid Digest, Laguna Niguel, v. 66, n. 4, p.165-177, 2002.

WANG, Y. T. Impact of Salinity and media on growth and flowering of a hybrid Phalaenopsis orchid. HortScience, Alexandria, v. 33, n. 2, p.247-250, 1998.

WHITHAM, F. H.; BLAYDES, D. F.; DEVLIN, R. M. Experiment in plant physiology. New York: Van Nostrand Company, 1971. 236 p. 